Bensing, J.M., Deveugele, M., Moretti, F., Fletcher, I., Vliet, L. van, Bogaert, M. van, Rimondini, M. How to make the medical consultation more successful from a patient's perspective? Tips for doctors and patients from lay people in the United Kingdom, Italy, Belgium and the Netherlands. Patient Education and Counseling!b $21 \mathrm{~A} \mid$ 84(3), 287-293

\begin{tabular}{|l|l|}
\hline Postprint Version & 1.0 \\
\hline Journal website & $\underline{\text { http://www.sciencedirect.com/science/article/pii/S0738399111003569 }}$ \\
\hline Pubmed link & $\underline{\text { http://www.ncbi.nlm.nih.gov/pubmed/21795007 }}$ \\
\hline DOI & 10.1016/j.pec.2011.06.008 \\
\hline
\end{tabular}

This is a NIVEL certified Post Print, more info at http://www.nivel.eu

\title{
How to make the medical consultation more successful from a patient's perspective? Tips for doctors and patients from lay people in the United Kingdom, Italy, Belgium and the Netherlands
}

\author{
JOZIEN M. BENSING ${ }^{\mathrm{A}, \mathrm{B}}$, , MYRIAM DEVEUGELE ${ }^{\mathrm{C}}$, FRANCESCA MORETTI ${ }^{\mathrm{D}}$, IAN FLETCHER ${ }^{\mathrm{E}}$, LIESBETH VAN \\ VLIET $^{\mathrm{A}}$, MARJOLEIN VAN BOGAERT ${ }^{\mathrm{C}}$ AND MICHELA RIMONDINI ${ }^{\mathrm{D}}$ \\ ${ }^{a}$ NIVEL (Netherlands Institute for Health Services Research), Utrecht, The Netherlands \\ ${ }^{\mathrm{b}}$ Utrecht University, Department of Clinical and Health Psychology, Utrecht, The Netherlands \\ ${ }^{c}$ Ghent University, Department of General Practice and Primary Health Care, Gent, Belgium \\ ${ }^{d}$ Verona University, Department of Medicine and Public Health, Section of Psychiatry and Clinical \\ Psychology, Verona, Italy \\ e University of Liverpool, Division of Clinical Psychology, Liverpool, United Kingdom
}

\begin{abstract}
Objective: The aim of this study is to generate empirically based 'tips' from lay people on how medical consultations could become more successful from a patient perspective.

Methods: 258 Lay people in the United Kingdom, Italy, Belgium and the Netherlands, distributed over 32 focus groups, were invited to formulate 'tips' for doctors as well as patients after rating the quality of communication from videotaped consultations and discussing their arguments in focus groups.

Results: Tips were remarkably similar across the four countries. Most tips reflect the professional literature, such as the importance of nonverbal communication, personal attention and empathy, but also addressed issues as how to deal with new technologies and new accessibility arrangements (triage). The tips were targeted to the consultation itself, its preparation and the aftercare. Tips for doctors were mirrored in tips for patients.

Conclusion: Lay people seem to be competent in participating in quality-of-care debates. They are well aware of patients' own responsibilities. Besides, they have clear opinions about novel technology and healthcare arrangements (triage).

Practice implications: Listening to patients, showing empathy and personal attention seem to have a universal value. Doctors should be trained to practice these behaviors, healthcare managers in involving patients in practice reorganisations.
\end{abstract}

\section{INTRODUCTION}

Most doctors, health care managers and policy makers will say that the patients' position is central to health care; unfortunately, despite this advocacy, patients seem to be easily overlooked. Debates on the quality of care [1], the cost-effectiveness of certain interventions [2], or interventions for practice 
Bensing, J.M., Deveugele, M., Moretti, F., Fletcher, I., Vliet, L. van, Bogaert, M. van, Rimondini, M. How to make the medical consultation more successful from a patient's perspective? Tips for doctors and patients from lay people in the United Kingdom, Italy, Belgium and the Netherlands. Patient Education and Counseling! $21 \mathrm{~d} / \mathrm{e}$ 84(3), 287-293

improvement [3] largely pass over patients' heads, and despite good intentions, the patient perspective is seldom taken into sufficient account. Patient involvement is often met with polite nods but little enthusiasm [3]. 'We know best what is best for you' is still a prevalent attitude [4].

For many reasons, it is understandable that patient involvement in health care issues is still more about words than deeds, a major reason being that in the long history of medicine this is only a fairly recent trend and we are simply not yet used to it. Changing habits is always a stubborn process. Furthermore, there are several realistic problems and barriers, including the lack of reliable and valid instruments for measuring patient views [5] and 6], the inevitable non responsive bias when recruiting people for this task [6], [7] and [8], the high ceiling effects in patient satisfaction scores [7] and [9], the subjective character of patient evaluations [10], the heterogeneity of the assessed case mix [7] and [11], and the lack of a standardized frame of reference [1] and [7]. It is no wonder that many people are still skeptical about the usefulness of patient assessments of the quality of care and are reluctant to implement it at a large scale.

Nevertheless, Governments of most European countries want more consumer involvement [12], [13], [14], [15] and [16] and also many doctors are authentic in their wish to involve patients in the way health care should be organised and delivered. This is also reflected in the growing interest in how patients or lay people can be used as teachers [17]. As early as 20 years ago, it was shown that lay persons are well equipped to assess the quality of communication of doctors and that doctors are willing to learn from 'patients as teachers'. So there seems to be a lot of unused potential which might help to increase the success of medical consultation from a patient perspective, which argues for a more systematic involvement of lay people in quality assessment of medical consultations. Moreover a larger involvement might help lay people to become more fully aware of their own responsibilities in medical consultations. The aim of this study is to generate empirically based 'tips' for doctors as well as patients on how medical consultations can become more successful from a patient perspective.

\section{METHODS}

This study is a part of a multicenter study focusing on lay peoples' preferences on general practitioner relational/communication style through the use of mixed methods of analysis, qualitative (i.e. focus groups) and quantitative (i.e. rating scales). The study got his name (GULiVer) from the four participating centers: Gent University (Belgium), Utrecht University/NIVEL (the Netherlands), Liverpool University (United Kingdom) and the Verona University (Italy). A description of GULiVer design and methods is provided elsewhere [18], here only the part connected to the aims of this part of the study is described.

\subsection{Study sample}

Data-collection took place in 2008-2009. The aim was to recruit participants in a context not related to their own medical consultation, in order to let them feel free to express the whole range of their opinions, positive as well as critical ones. Therefore, lay people were randomly recruited in and around, Ghent,

Utrecht, Liverpool and Verona. People were approached in public areas, such as shopping centers, via calls in free local papers, and by snowballing. Exclusion criteria were: age under 18, no GP-visit over the last 12 months, recent involvement in medically related lawsuits or complaint procedures, and insufficient mastery of the countries language [18]. Participants were financially compensated for participation according to the guidelines of INVOLVE, a NIHR-funded organisation to promote public involvement in NHS, public health and social care research [19]

In total 258 participants were included over the four countries. People were purposively assigned to focus groups to get a balanced age-gender distribution. The focus groups were held partly on weekdays and partly on Saturdays. In each country 8 or 9 focus groups were organised with 6-9 participants each. Background characteristics are presented in Table 1. Participants in the three countries were comparable in age, gender, communication preferences and trust in health care, but, the UK participants proved to be higher educated, more often married and employed, and had a better health, compared to the participants in Italy and in the Netherlands.

\section{[TABLE 1]}


Bensing, J.M., Deveugele, M., Moretti, F., Fletcher, I., Vliet, L. van, Bogaert, M. van, Rimondini, M. How to make the medical consultation more successful from a patient's perspective? Tips for doctors and patients from lay people in the United Kingdom, Italy, Belgium and the Netherlands. Patient Education and Counseling! $21 \mathrm{~d} / \mathrm{e}$ 84(3), 287-293

\subsection{Research material}

In order to provide a homogeneous frame of reference, the participants were provided with a set of standardized videotaped medical consultations, which were recorded as part of the summative 4th year medical exams (OSCEs) at Liverpool Medical School assessing competency of communication. Two scenarios were used: vaginal discharge related to unsafe sex with an unknown partner and a possible diagnosis of sexual transmitted disease (STD) and serious period pain (PP) resulting in absenteeism from work making the patient anxious for losing her job. The videotapes were selected based on the quality ratings of the examiner and the standardized patient involved. From the available videos $(n=166) 4$ videos from each scenario were selected according to their SP and the examiner score to maximize the variability in the quality of communication. The same set of videos was used in all four countries. The videos were either dubbed (Italy) or subtitled (the Netherlands and Belgium) to conform to the accepted practice of displaying English language television programs across countries.

\subsection{Procedure}

In the first part of the focus group meetings four different videos of the same scenario were shown to the participants. According to a strict protocol the participants were asked to give a quality rating on the doctor's communication and to discuss their arguments within the focus group. During the last hour of the focus group meeting, the participants were invited to formulate tips for doctors as well as patients that could make the medical consultation more successful from a patient perspective. The facilitator encouraged participants to be open and creative ('there are no wrong views; we are interested in every individual opinion'), and to use the results of the earlier focus group discussions as well as their own personal experience with health care when formulating their tips. The facilitators took care to restrict their own role to guiding discussions and not to offer their own content/views, which might have influenced the debate. All sessions were audio-taped and transcribed to facilitate analyses.

\subsection{Analysis}

The first two steps in the coding were done locally. First, one author per country (FM, MB, IF, LV) removed idiosyncratic tips, which were suggested by an individual participant that were not supported and/or mentioned by other participants. Second, all the remaining tips were integrated into a local document for each country. All authors per country were involved in checking this integrated list of tips. At this stage all material was translated into English. Next, the four local documents were compared during a two-days meeting, based on a preparatory overview of the material. To ensure reliability, all authors discussed the tips and ordered them according to the main topics they referred to while constant comparing tips between and within countries. Disagreement was solved by consensus. Subsequently, the tips were shortened and synthesized. The resulting tips were put into a table with separate columns for doctor and patient. In a last step to achieve reliable results, the researchers from each country checked the final table against their original material and confirmed that all relevant tips were included.

\section{RESULTS}

\subsection{Main findings}

An overview of the tips formulated by the participants is presented in Table 2 .

\section{[TABLE 2]}

The tips could be clustered in three different timeframes: before, during and after the consultation. The most mentioned topics or each phase were (see Table 2)

- before the consultation: doctor and patient both have to be prepared for the consultation, the doctor by reading the notes from previous consultations, being aware of the patient's cultural background and keeping an open mind without prejudices; the patient by keeping notes about the development of symptoms and reflecting on his/her expectations for this particular consultation. Moreover: direct access to the doctor without interference by a practice nurse or receptionist (screening, triage) is seen as very important by the respondents, in particular when patients have new health problems. Our respondents had no problem with seeing auxiliary health professions for the monitoring of chronic diseases. 
Bensing, J.M., Deveugele, M., Moretti, F., Fletcher, I., Vliet, L. van, Bogaert, M. van, Rimondini, M. How to make the medical consultation more successful from a patient's perspective? Tips for doctors and patients from lay people in the United Kingdom, Italy, Belgium and the Netherlands. Patient Education and Counseling!b 84(3), 287-293

- during the consultation: doctor has to take the patient seriously, be empathic and supportive and treat him/her as a human being instead of a 'bundle of symptoms', while patients have to be honest, open and realistic, neither exaggerating nor underplaying the seriousness of their health problem. Patients have to be assertive; doctors have to inform patients. While time management is primarily the doctor's responsibility, the management of expectations is seen as a responsibility of doctor and patient.

- after the consultation: doctor and patient are both responsible for the continuity of care: the doctor by giving test results even when these are normal, the patient by informing the doctor on success or failure of the treatment (this can be done by email). Furthermore, doctors should inform their patients about possible alarm signals and show their willingness to follow-up, while patients have to adhere to treatment and take responsibility over their own treatment. The integration of modern information technology (the use of proper websites, email) into usual health care is a responsibility of both, as is talking about it during the consultation.

\subsection{Similarity between the countries}

Nearly all topics were mentioned in one way or another across all four countries. The most outspoken tip in all countries was that doctors should really listen and show personal attention and empathy (see Box 1 for quotes):

There were three exceptions to the homogeneity of patient tips in the four participating countries:

\section{[BOX 1]}

(1) In Belgium and in Italy there was no discussion about problems with direct access to the doctor through interference by receptionists or nurses who were acting as gatekeepers for primary care (triage). However, in the UK and the Netherlands, this triage-system led to many critical comments:

(UK, male): Tell the receptionist to stop diagnosing the patients...

(NL, female): Yes I was going to say, the receptionist is the worse bit of going to the doctor.

(2) All countries formulated tips for doctor as well as for the patient, but although this also happened in Belgium, the number of tips for patients was lower as compared to the other countries. Belgian participants answered the task by looking almost exclusively to the doctors' part of the consultation. Nevertheless the scarce tips for patients given by the Belgian participants were the same as those given by the other countries.

(Belgium, female): The doctor has to give explanation about everything, but the patient has to ask questions if something is not clear. When I go to the doctor and he does not give me the information I want, I just ask for it.

(3) The last notable difference is that while in the UK and the Netherlands, the respondents were quite critical towards doctors, articulating clearly their expectations, in Italy, the respondents were more aware of the power distance between doctor and patient, although their tips covered the same topics as compared to the other countries.

(Italy, male): The attitude towards the doctor as someone who is "above the patient" should be avoided. The doctor should be more considered as an instrument. E.g. While the doctor is explaining something, he does not do you a favor; he is just doing his work; it is his duty to inform you. The patient should be more aware of his right, should try to have a more confident attitude towards the doctor.

\subsection{Similarity in tips for doctor and for patients}

Reviewing the tips that were generated by the focus groups led to the observation that the responsibility for a successful medical consultation was explicitly located in both doctor and patient. As a consequence, many of the tips for doctors had a mirror image in the tips for patients, for instance: a careful preparation, respect and empathy for the other party, openness and honesty in providing information, management of questions and expectations, investment in a common agenda, and awareness of potentially disturbing factors in the context of the medical consultation (see Table 2).

- (tip for doctors regarding question-asking): Give the patients a chance to ask questions. Ask them if they have got anything they would like to ask. 
Bensing, J.M., Deveugele, M., Moretti, F., Fletcher, I., Vliet, L. van, Bogaert, M. van, Rimondini, M. How to make the medical consultation more successful from a patient's perspective? Tips for doctors and patients from lay people in the United Kingdom, Italy, Belgium and the Netherlands. Patient Education and Counseling! $21 \mathrm{~d} / \mathrm{e}$ 84(3), 287-293

- (tip for patients regarding question-asking): Don't be afraid to ask question if you don't understand something. Tell him that you don't understand.

Second, in all four countries participants stressed the importance of the continuity of care. A good consultation is part of a longer chain of events. For doctors, understanding the patients' reason for encounter is facilitated when knowing the medical, social and cultural background of the patient, for patients, keeping a symptom diary and articulating their questions and expectations prior to the consultation could speed up the process and make it more effective. In the eyes of the lay people from our study, the responsibility for the continuity of care is extended to the aftercare: doctors should always give patients their test results, even if no abnormal results were found; this can reassure patients as well as provide an additional check for administrative errors.

- (tip for doctors regarding continuity of care): Research their history and read the notes beforehand. Because I have gone in a number of times at their request to come down say a week later and they have said yes what are you here for. Well they should know. If it had been on the notes this person has been asked to come back, they would pick that up.

- (tip for patients regarding continuity of care): Before meeting your doctor try to have at least a clear idea of what to tell him. You could write down (before going to the doctor) a list of the things you'd like to tell him. You should try to be as concise as possible starting with saying the things you consider the most important.

\subsection{Dilemmas}

Not all discussions in the focus groups were easily transformed into tips. Sometimes lengthy discussions were held. In these cases, the moderator guided the focus group to try to articulate a tip which clarified the issue without giving simple solutions. We give two examples:

(a) Honesty: In nearly all focus groups, the value of honesty in mutual information giving was stressed. However, many participants were well aware that honesty is easier to preach than to practice. People might be afraid to tell everything to their doctor for fear for negative reactions e.g. the use of complementary medicine. People also restrict themselves because they have the impression that doctors are hurried (the tip for doctors to handle their own work stress in a professional way was based on this observation). On the other hand, some of the participants mentioned that not everybody appreciates complete honesty from the doctor, especially when the news is negative. This led to the tip that honesty should never result in bluntness, but always be sensitive to patients' needs and embedded in empathy (see

Table 2).

(b) Technology: A recurrent topic in many focus groups was the use of modern technology (computer, internet). While for most people the introduction of new technologies in health care was inevitable and worthwhile, there was a lot of discussion on the negative sides as well. Many participants complained that the computer was literally a barrier between doctor and patient. A participant from the UK remarked that it would be helpful if the computer was not only considered as a tool for the doctor, but was conceived and handled as a potential tool for patients as well e.g. by printing information from their medical record, or allowing patients to watch what information is recorded. The discussion emphasized that involving patients in recording information might help to prevent errors. Patients also have to learn how to use new technologies. In many focus groups there was a discussion on the use of internet. While most people agreed that internet was a valuable source of information, some (but not all) people remarked that it would be better for patients to start looking for information subsequent to visiting the doctor, rather than before to minimize unjustified worries. The role of the Government in safeguarding the quality of medical information on the internet was mentioned in all countries.

\section{DISCUSSION AND CONCLUSION}

\subsection{Discussion}

The study demonstrates that it is feasible to involve lay people in research. It proved to be very easy to recruit the participants, probably partly because of the financial compensation ( $€ 150$ for a day's work), which was seen as fair and attractive, but also because they had a genuine interest in the topic of the study and appreciated the fact that they could work in a project which was important to them. The participants took their work seriously, were thoughtful and nuanced in their arguments and generally constructive. 
Bensing, J.M., Deveugele, M., Moretti, F., Fletcher, I., Vliet, L. van, Bogaert, M. van, Rimondini, M. How to make the medical consultation more successful from a patient's perspective? Tips for doctors and patients from lay people in the United Kingdom, Italy, Belgium and the Netherlands. Patient Education and Counseling! bld 1 , 84(3), 287-293

Positive and critical opinions were articulated in the same balanced way. We did notice neither 'doctorbashing', nor naïve idealization. This supports our choice of recruiting lay people for this quality assessment task. Of course we do not know to what extent the lay people's opinions are congruent with patients' opinions right after a medical visit. But the fact that - in formulating their 'tips' - the participants mixed their observations of the shown videos with personal experiences with health care provides some validity to the study results.

The similarity in lay people's tips over the four countries was striking. However, there were also some remarkable differences between the countries which could be interpreted within the context of differences in existing health care systems. A good example is the tip regarding the importance of direct access to the doctor without interference by a nurse or receptionist (triage system), which was only articulated in those countries in which direct access is under pressure (UK and the Netherlands). In English and Dutch focus groups, this topic evoked much discussion. In Italy, there is no triage in General Practice, while in Belgium, it is just introduced in only a few locations. In these countries the issue of direct accessibility of the GP did not come up at all. This finding illustrates how international studies, conducted from a patient perspective, can provide valuable knowledge about how changes in the health care system are or are not appreciated by patients and the general public.

The success of medical consultations was explicitly seen as a joint responsibility of doctor and patient. In the eyes of the participants in our study, both parties have to make a contribution to the success of medical consultations ("it takes two to tango"), and many of the articulated 'tips' for doctors are mirrored in comparable 'tips' for patients. This is an interesting finding, because it shows the maturing of patient empowerment, which - according to this study - is not only about patient rights but also about patient obligations, resulting in a more balanced doctor-patient relationship. The medical establishment does not need to be reticent about involving lay people in the development of criteria for good quality of care.

Many of the 'tips' formulated by the lay people from this study correspond with what is known from the professional literature about patient-centered communication [20], [21], [22] and [23], such as - the importance of silence, listening and nonverbal communication (eye contact) in order to facilitate a dialogue instead of having monologues - the value of empathy and respect in creating an effective doctor - patient relationship - the need to address patients as individual persons, and not as 'a bundle of symptoms'. These tips may seem general, but are of universal value for lay people in these four Western countries, as was illustrated by the provided quotes.

The tips also refer to issues which are still under debate in the professional literature and in need for further professional advancement, such as - should doctors take for granted that all patients always want to receive all medical information and be involved in all decision making? [24] and [25] - how should new communication technologies (computer, telemedicine, internet) be integrated in modern medical care? [26] and [27] - how could the role of context factors in the delivery of health care be optimized and the downsides be minimized [28]. To what extent do the benefits of triage systems in General Practice outweigh the drawbacks of building barriers for direct GP consultations? [29], [30] and [31]. Our study shows that lay people do have clear and balanced opinions on these issues, sometimes outspoken in the case regarding the triage system in two countries (UK and the Netherlands).

\subsubsection{Limitations of the study}

The tips were formulated after watching and discussing videotapes of 4th year medical students during an exam. This situation is different from usual care. However, the OSCE's were meant to test communication performance and proved to be a good trigger for evoking discussions about the adequacy of communication from a patient perspective. In this, we valued the advantage of having a set of standardized stimuli over the perhaps higher ecological validity of natural medical consultations. Another possible limitation is related to the content of the consultations: gyneacological consultations with psychosocial elements, involving taboo topics. The potential risk of embarassment was solved by creating same gender focus groups, and this proved to be a good strategy, as discussions were lively and everybody participated. No gender differences in tips were found. Although the tips are based on a fairly large sample (258 participants and 33 focus groups in four Western countries), we cannot guarantee that these tips can be generalized to lay people in general', as only Western European countries were involved, and there were differences in the background characteristics of the participants in the four countries. Furthermore, our recruitment process excluded 
Bensing, J.M., Deveugele, M., Moretti, F., Fletcher, I., Vliet, L. van, Bogaert, M. van, Rimondini, M. How to make the medical consultation more successful from a patient's perspective? Tips for doctors and patients from lay people in the United Kingdom, Italy, Belgium and the Netherlands. Patient Education and Counseling! 84(3), 287-293

participants involved in formal complaint procedures, who may have had a different perspective. Moreover, while the procedure guarantees that all tips which were collected in a country were actually involved in the final list, the reverse was not always the case, as was shown above. Therefore it would be worthwhile to develop a follow-up study in which these 'tips' are sent to larger samples, preferably also in EasternEuropean countries. Nevertheless, we think that the results of this study are fairly robust and could be a source of inspiration for patients, doctors and their respective organisations.

\subsection{Conclusion}

Lay people seem to be competent in participating in quality-of-care debates. As the outcome of these debates may have a direct and often profound influence on the potential users of health care, it is important as well as feasible to give lay people a voice in quality-of-care debates.

\subsection{Practice implications}

This study has shown that lay people's opinions are a valuable asset in debates on the quality of care, showing the strong but also the vulnerable aspects of health care. Within the medical consultation room, listening to patients, taking them seriously, and showing empathy have proven to be of universal value for people in these four countries. Therefore, doctors should be trained to practice these behaviors and not mainly focusing on maximizing efficiency. This is also a clear message to the health care funding authorities. Moreover, health care organisations, professional organisations could develop instruments like the methodology of this study to stimulate quality-debates among their patients, former patients or potential patients. Patient organisations could do the same for their members, with interactive websites as a new, innovative and efficient medium to do so. Our study shows that people are keen to participate in such initiatives. The first challenge is to invest in methods to give patients a voice in health care debates, and the second is to listen carefully to what they have to say.

\section{Funding}

This study was partly supported by a grant from Fund PGO (Ministry of Health, the Netherlands), and partly by the authors' own universities/research institutes. No author has received any financial benefit from research in this study.

Role fund PGO: The funder had no role in the collection, analysis and interpretation of the data, even as in writing the article.

Independence of researchers: All authors declare that they behaved independently of the funding organisation PGO.

Access of data: All authors have full access to all the obtained data.

\section{Contributors}

JB conceived the idea for the study. JB, IF, FM, MR contributed to the design of the study and collection of the material. JB, IF, FM, MR, and LV contributed to the qualitative analysis and interpretation of the results. All authors contributed to the writing of the paper. JB is the guarantor.

\section{Competing interest}

All authors declare that the answer to the questions on your competing interest form are all No and therefore have nothing to declare.

\section{Ethical approval}

The project was approved by the Medical Education Research Ethics Committee of the University of Liverpool. Informed consent from all participating lay people was obtained in all four countries.

\section{Acknowledgments}

- Fund PGO (Ministry of Health, the Netherlands) for financial support.

- Medical School of Liverpool University for making the videotaped consultations available.

- All lay people who contribute to this project; without their devoted and sincere efforts, this project would not have been possible. 
Bensing, J.M., Deveugele, M., Moretti, F., Fletcher, I., Vliet, L. van, Bogaert, M. van, Rimondini, M. How to make the medical consultation more successful from a patient's perspective? Tips for doctors and patients from lay people in the United Kingdom, Italy, Belgium and the Netherlands. Patient Education and Counseling! $21 \mathrm{~d} / \mathrm{e}$ 84(3), 287-293

\section{REFERENCES}

[1] G. Elwyn, S. Buetow, J. Hibbard and M. Wensing, Measuring quality through performance. Respecting the subjective: quality measurement from the patient's perspective, Brit Med J 335 (2007), pp. 10211022.

[2] J. Speight and M. Reaney, Wouldn't it be NICE to consider patients' views when rationing health care?, Brit Med J (2009), p. b85.

[3] G. Elwyn, A.M. O'Connor, C. Bennett, R.G. Newcombe, M. Politi and M.A. Durand et al., Assessing the quality of decision support technologies using the International Patient Decision Aid Standards instrument (IPDASi), PLoS One 4 (2009), p. e4705.

[4] N. Hawkes, Why l'm nostalgic for community health councils, Brit Med J 338 (2009), p. 1301.

[5] J. Sitzia, How valid and reliable are patient satisfaction data? An analysis of 195 studies, Int J Qual Health Care 11 (1999), pp. 319-328.

[6] M. Wensing and G. Elwyn, Methods for incorporating patients' views in health care, Brit Med J 326 (2003), pp. 877-879.

[7] G.E. Rosenthal and S.E. Shannon, The use of patient perceptions in the evaluation of health-care delivery systems, Med Care 35 (1997), pp. NS58-NS68.

[8] K.M. Mazor, B.E. Clauser, T. Field, R.A. Yood and J.H. Gurwitz, A demonstration of the impact of response bias on the results of patient satisfaction surveys, Health Serv Res 37 (2002), pp. 1403-1417.

[9] S. Cheraghi-Sohi and P. Bower, Can the feedback of patient assessments, brief training, or their combination, improve the interpersonal skills of primary care physicians? A systematic review, BMC Health Serv Res 8 (2008), p. 179.

[10] M. Rao, A. Clarke, C. Sanderson and R. Hammersley, Patients' own assessments of quality of primary care compared with objective records based measures of technical quality of care: cross sectional study, Brit Med J 333 (2006), pp. 19-24.

[11] A. Donabedian, Evaluating the quality of medical care, Milbank Q 83 (2005), pp. 691-729.

[12] D. Florin and J. Dixon, Public involvement in health care, Brit Med J 328 (2004), pp. 159-161.

[13] Ministerie van VWS. Programma "Zeven rechten voor de cliënt in de zorg: Investeren in de zorgrelatie"; 2008. [Ministry of Public Health, Welfare and Sports. [Programme "Seven rights for clients in healthcare: Investing in the healthcare relationship"]. the Hague, the Netherlands; 2008.

[14] Dipartimento della qualità. Direzione Generale della Programmazione Sanitaria, dei Livelli Essenziali di Assistenza e dei Principi Etici di Sistema. "Analisi e condivisione delle esperienze di Governo Clinico"; 2005. [Department of Quality. General Ministry of Health Planning, the basic level of service and ethical principles of the system. "Analysis and sharing of experience of Clinical Governance". Rome, Italy; 2005].

[15] C. Goss and C. Renzi, Patient and citizen participation in health care decisions in Italy, Z Arztl Fortbild Qualitatssich 101 (2007), pp. 236-240.

[16] Department of Health. The NHS plan: a plan for investment, a plan for reform, London, United Kingdom; 2000.

[17] G. Wykurz and D. Kelly, Developing the role of patients as teachers: literature review, Brit Med J 325 (2002), pp. 818-821.

[18] Moretti F, Fletcher I, Mazzi MA, DeVeugele M, Rimondini M, Geurts C, et al. GULiVER-travelling into the heart of good doctor-patient communication from a patient perspective. A multicentre study. EJPH 2011, Jun 28 [Epub ahead of print].

[19] INVOLVE. A guide to reimbursing and paying members of the public who are actively involved in research: For researchers and research commissioners (who may also be people who use services), Revised version. August, Eastleigh, Hampshire, United Kingdom; 2006.

[20] L.M. Ong, J.C. de Haes, A.M. Hoos and F.B. Lammes, Doctor-patient communication: a review of the literature, Soc Sci Med 40 (1995), pp. 903-918.

[21] J.M. Bensing and P.F.M. Verhaak, Communication in medical encounters. In: A.A. Kaptein and J.

Weinman, Editors, Health psychology, Blackwell Publishing, Oxford, United Kingdom (2004) pp. $261-287$.

[22] D. Roter and J.A. Hall, Doctors talking with patients/patients talking with doctors: improving communication in medical visits, Praeger, Westport, Conn (2006).

[23] M.A. Stewart, Effective physician-patient communication and health outcomes: a review, CMAJ 152 (1995), pp. 1423-1433. 
Bensing, J.M., Deveugele, M., Moretti, F., Fletcher, I., Vliet, L. van, Bogaert, M. van, Rimondini, M. How to make the medical consultation more successful from a patient's perspective? Tips for doctors and patients from lay people in the United Kingdom, Italy, Belgium and the Netherlands. Patient Education and Counseling!b $21 \mathrm{~A} \mid$ 84(3), 287-293

[24] S.A. Kaplowitz, S. Campo and W.T. Chiu, Cancer patients' desires for communication of prognosis information, Health Commun 14 (2002), pp. 221-241. via CrossRef | View Record in Scopus | Cited By in Scopus (48)

[25] W. Levinson, A. Kao, A. Kuby and R.A. Thisted, Not all patients want to participate in decision making. A national study of public preferences, J Gen Intern Med 20 (2005), pp. 531-535.

[26] D. Greatbatch, C. Heath, P. Campion and P. Luff, How do desk-top computers affect the doctor-patient interaction?, Fam Pract 12 (1995), pp. 32-36.

[27] J.M. Bensing, F. Tromp, S. van Dulmen, A. van den Brink-Muinen, W. Verheul and F.G. Schellevis, Shifts in doctor-patient communication between 1986 and 2002: a study of videotaped general practice consultations with hypertension patients, BMC Fam Pract 7 (2006), p. 62.

[28] Z. Di Blasi, E. Harkness, E. Ernst, A. Georgiou and J. Kleijnen, Influence of context effects on health outcomes: a systematic review, Lancet 357 (2001), pp. 757-762. View Record in Scopus | Cited By in Scopus (313)

[29] M. Offredy and J. Townsend, Nurse practitioners in primary care, Fam Pract 17 (2000), pp. 564-569.

[30] D.A. Richards, J. Meakins, J. Tawfik, L. Godfrey, E. Dutton and G. Richardson et al., Nurse telephone triage for same day appointments in general practice: multiple interrupted time series trial of effect on workload and costs, Brit Med J 325 (2002), p. 1214.

[31] M.A. Inness, Telephone triage - simple idea, complex communication skill, Brit Med J 28 (2002).

\section{TABLES AND BOX}

\section{Table 1}

Background characteristics of the participants.

\begin{tabular}{|c|c|c|c|c|c|}
\hline & $\mathrm{BE}$ & NL & IT & UK & Total \\
\hline Sample size & 48 & 63 & 72 & 75 & 258 \\
\hline \multicolumn{6}{|l|}{ Age $(n)$} \\
\hline \multicolumn{6}{|l|}{ Male } \\
\hline $18-30$ & 10 & 10 & 10 & 9 & 29 \\
\hline $31-50$ & 6 & 9 & 14 & 16 & 37 \\
\hline$>51$ & 5 & 10 & 9 & 9 & 30 \\
\hline \multicolumn{6}{|l|}{ Female } \\
\hline $18-30$ & 9 & 14 & 14 & 10 & 29 \\
\hline $31-50$ & 9 & 10 & 12 & 16 & 42 \\
\hline$>51$ & 9 & 10 & 13 & 15 & 38 \\
\hline $\begin{array}{l}\text { Education: } \geq \text { high } \\
\text { school (\%) }\end{array}$ & 56.3 & 38.1 & 60.0 & 36.1 & 47.3 \\
\hline $\begin{array}{l}\text { Married/living } \\
\text { together }(\%)\end{array}$ & 44.7 & 42.9 & 33.4 & 60.0 & 45.4 \\
\hline Employed (\%) & 47.9 & 29.0 & 55.6 & 86.7 & 56.8 \\
\hline
\end{tabular}


Z Tips from lay people for doctors and patients.

\begin{tabular}{|c|c|}
\hline Tips for doctors & Tips for patients \\
\hline $\begin{array}{l}\text { Before the consultation } \\
\text { - Give patients the opportunity for meeting the doctor without screening } \\
\text { by a receptionist } \\
\text { - Prepare the consultation; know who is coming and what the medical } \\
\text { background is } \\
\text { - Gain knowledge about the patients' cultural background } \\
\text { - Avoid prejudice; keep an open mind } \\
\text { - Write on the wall: "what do you expect from the doctor?" } \\
\text { in order to stimulate patients to reflect on it before entering }\end{array}$ & $\begin{array}{l}\text { - Go to the doctor if it is needed, but don't use him/her } \\
\text { as a substitute for your social life } \\
\text { - Prepare yourself well: } \\
\text { - keep a diary of your symptoms } \\
\text { - write down what you want to ask } \\
\text { - reflect on your expectations } \\
\text { - know which medicines you take } \\
\text { - Take a companion, if you think that you might need support } \\
\text { - Keep your appointment! }\end{array}$ \\
\hline $\begin{array}{l}\text { During the consultation } \\
\text { - Introduce yourself with unknown patients } \\
\text { - Show patients that they are welcome } \\
\text { - Keep eye contact } \\
\text { - Listen; don't interrupt the patient } \\
\text { - Show compassion; be empathic } \\
\text { - Pay attention to psychosocial issues } \\
\text { - Take your time; don't show your hurry } \\
\text { - Treat patients as human beings and not as a bundle of symptoms } \\
\text { - Take the patient seriously } \\
\text { - Be honest without being rude } \\
\text { - Avoid jargon, check if the patient understands } \\
\text { - Know your limits; know when you have to refer a patient } \\
\text { - Invest in a common agenda } \\
\text { - Avoid disturbances by computer or telephone }\end{array}$ & $\begin{array}{l}\text { - Take notes } \\
\text { - Be honest about your medical problem, don't exaggerate, } \\
\text { don't underplay your symptoms, and don't be embarrassed } \\
\text { - Tell your doctor what you already did yourself to relieve the } \\
\text { symptoms, including self-medication and complementary medicine } \\
\text { - Be assertive: tell the doctor what you expect } \\
\text { - Ask for clarification if something is not clear } \\
\text { - Tell the doctor about relevant psychosocial issues } \\
\text { - Ask for benefits, side effects and alternative options } \\
\text { - Ask what you can do yourself } \\
\text { - Be realistic; don't expect miracles; the doctor is no God } \\
\text { - Be aware that there are other patients } \\
\text { - Don't leave before you are satisfied with the treatment plan, or } \\
\text { ask for a new appointment }\end{array}$ \\
\hline $\begin{array}{l}\text { After the consultation } \\
\text { - Give the patient always the test-results, even if these are ok } \\
\text { - Give the patient clear instructions what to do under certain circumstances } \\
\text { - Give explicit opportunity for email contact } \\
\text { - Offer sources of (trusted) information (websites; leaflets) }\end{array}$ & $\begin{array}{l}\text { - Adhere to the agreed treatment plan } \\
\text { - Inform your doctor on treatment results (could be done per email) } \\
\text { - Collect additional information from trusted sources } \\
\text { - Respect your doctors privacy } \\
\text { - Find another doctor if you are not satisfied, but, first, try to } \\
\text { talk about your discontentment }\end{array}$ \\
\hline
\end{tabular}


Bensing, J.M., Deveugele, M., Moretti, F., Fletcher, I., Vliet, L. van, Bogaert, M. van, Rimondini, M. How to make the medical consultation more successful from a patient's perspective? Tips for doctors and patients from lay people in the United Kingdom, Italy, Belgium and the Netherlands. Patient Education and Counseling! $201 \mathrm{~A}$ 84(3), 287-293

Box 1. Quotes of participants regarding the tip for doctors to listen and show personal attention and empathy

(UK, male): Basically the main one is manner, the way you deal with people, and the way you bring the information out of the patient and that is this business of having empathy with the person.

(UK, female): Doctors need to be attentive but they also need to personalise their approach.

(NL, male): I find it important that doctors really listen, that a doctor shows in everything, verbally and nonverbally, that he is really listening and that he has time for you, that you are allowed to finish your story.

(NL, female): When you are there, you want, of course that the doctor takes time for you. You are there, and so you want to be heard... And you don't want the doctor to be inattentive, that you have to repeat yourself. Yes, that is what you want: you want to be heard.

(Italy, male): Put the patient at ease, show empathy to the patient, having a warm attitude, a bit of humor, being friendly. These attitudes put the doctor and the patient at the same level: two human beings, two people who are trying to collaborate for the same result.

(Italy, female): Be committed to the patient, show to be interested and focused on the patient and his problems, and do not get distracted. Sometimes it looks like doctors hear you but they do not really listen to you... A doctor should show empathy to the patient, and look the patient in the eyes.

(Belgium, male): The doctor has to listen carefully, because dealing with someone of 15 years of age is totally different from someone of 60 . He has to gain confidence and that is different with a child or an adolescent.

(Belgium, female): The doctor has to listen to the patient because he has to engage the patient in the discussion, and that is only possible if the doctor listens carefully. Furthermore, being empathic is very important, the doctor must have an open attitude, he must be prepared to accept what the patient is saying. The doctor has to show an attitude like 'I am open for every question you want to ask'. 